\section{ORIGINAL RESEARCH}

\author{
X. Lv \\ Y. Li \\ C. Jiang \\ Z. Wu
}

\title{
Endovascular Treatment of Brain Arteriovenous Fistulas
}

BACKGROUND AND PURPOSE: Brain arteriovenous fistulas (BAVFs) are dangerous lesions with significant risks for hemorrhage and re-hemorrhage; thus, the management of BAVFs is an important subject. Flow disconnection can be accomplished by surgical or endovascular techniques. We reviewed the experience in our endovascular treatment of patients with BAVFs.

MATERIALS AND METHODS: From March 2006 to March 2008, a total of 9 consecutive patients with nontraumatic BAVFs were treated at Beijing Tiantan Hospital. Dural arteriovenous fistulas and Galen aneurysmal malformations were excluded from this study. We retrospectively reviewed the medical records, cerebral angiograms, and endovascular reports for each patient. Radiographic outcome was assessed by posttreatment angiography. Clinical outcome was assessed for every patient.

RESULTS: There were 9 patients with a total of 11 BAVFs. The mean age at presentation was 17.8 years. The clinical presentations were intracranial hemorrhage in 4 patients, headaches in 2 patients, and seizure in 1 patient, with 2 patients diagnosed incidentally. All lesions were supratentorial, and a venous varix was found on angiographic examination. Seven patients were treated with coils, 1 with Onyx-34, and 1 with a combination of coils and glue. All 9 lesions were completely obliterated as demonstrated on follow-up angiographic examination. With a mean follow-up of 5.7 months (range, 3-12 months), all patients were neurologically excellent with no symptoms (modified Rankin Scale, 0).

CoNCLUSIONS: BAVFs are more frequent in younger patients and frequently lead to intracranial hemorrhage. Staged endovascular coil embolization of BAVFs may be a good appropriate treatment technique.

B rain arteriovenous fistulas (BAVFs) are rare neurovascular lesions of the brain (accounting for only 1.6\%-4.7\% of all brain AV malformations) that have been considered a distinct pathologic entity from other brain AV malformations (BAVMs). ${ }^{1,2}$ BAVFs differ from BAVMs in that they lack a true nidus and differ from dural arteriovenous fistulas (AVFs) in that they derive their arterial supply from pial or cortical arterial vessels, and the lesion does not lie within the dural leaflets. ${ }^{3,4}$ They are composed of a single venous channel in communication with 1 or more arterial connections, with no intervening nidus of vessels. ${ }^{2}$ Because of their high-flow nature, they often are associated with a venous varix and have a poor natural history. ${ }^{5-11}$ The pathologic aspects of BAVFs arise from their high-flow dynamics. The complex hemodynamics of large AVFs makes them challenging lesions to treat. Endovascular management of high-flow AVFs has not always been successful previously, and these malformations have to be treated with surgery, with or without endovascular techniques. ${ }^{12-19}$ In a review of the literature by Hoh et al ${ }^{14}$ of studies of 79 patients with BAVFs published between 1970 and 2000 , endovascular treatment had been attempted in 50 of these patients; however, in $40 \%$ of patients, this treatment had failed or the fistulas had required additional treatment. Of the 51 patients who underwent surgery, the attempt failed in only $7.8 \%$ patients. In 9 patents treated by Hoh et al, ${ }^{14} 6$ were treated with surgery, 2 were treated with endovascular technique, and 1 was treated with a combination of these 2 tech-

Received September 1, 2008; accepted after revisions October 25.

From the Beijing Neurosurgical Institute and Beijing Tiantan Hospital, Capital Medical University, Beijing China.

Please address correspondence to Youxiang Li, MD, Beijing Neurosurgical institute and Beijing Tiantan Hospital, Capital Medical University, 6 Tiantan, Xili, 100050, Beijing, China; e-mail: liyouxiang@263.net

DOI 10.3174/ajnr.A1436 niques. As endovascular technologies advance rapidly, we expect higher success rates with the endovascular approach. We reviewed our recent experience in endovascular treatment of BAVFs during a 2-year period.

\section{Materials and Methods}

From March 2006 to March 2008, a total of 9 consecutive patients with nontraumatic noniatrogenic BAVFs were treated with neuroendovascular techniques at Beijing Tiantan Hospital in Beijing, China. Conventional cerebral angiography was used to define the lesions for each patient. We strictly defined BAVFs for our study because these lesions had 1 or more direct arteriovenous connections with no intervening nidus. Dural AVFs and Galen aneurysmal malformations were excluded from this analysis. All lesions were treated with endovascular techniques. Medical records, cerebral angiograms, and endovascular reports were reviewed retrospectively. Clinical and angiographic follow-up was obtained for each patient. Clinical outcome was assessed according to the modified Rankin Scale.

\section{Patients}

There were 2 female patients and 7 male patients. The median age was 17.8 years (range, $2-40$ years). Presentation was by hemorrhage in 4 patients, headaches in 2 patients, seizure in 1 patient, and incidental in 2 patients. Management of hemorrhage was conservative in all patients who presented with intracranial hemorrhage. No patients underwent surgical evacuation of hemorrhage or required ventriculoperitoneal shunt surgery. All patients made full recoveries from their hemorrhage before treatment of their pial AVFs.

\section{Angiographic Characteristics}

The fistula locations of the 9 BAVFs are listed in the accompanying Table, as are the angiographically defined involved fistulous vessels. Eight AVFs were associated with large venous varices. None of the 


\begin{tabular}{|c|c|c|c|c|c|c|}
\hline \multicolumn{7}{|c|}{ Patients with BAVFs treated with endovascular techniques } \\
\hline $\begin{array}{l}\text { Patient } \\
\text { No. }\end{array}$ & Age/Sex & Location & Presentation & Feeding Arteries & $\begin{array}{l}\text { Treatment and Immediate } \\
\text { Outcome* }\end{array}$ & Follow-up \\
\hline 1 & $7 / \mathrm{M}$ & Gyrus rectus region & $\mathrm{ICH}$ & Junction of $A 1$ and $A 2$ & Onyx-34, complete & 3 \\
\hline 2 & $26 / F$ & $\begin{array}{l}\text { Posterior aspect of interhemispheric } \\
\text { fissure }\end{array}$ & Headaches & Distal ACA & Detachable coils, incomplete & 4 \\
\hline 3 & $7 / \mathrm{M}$ & Interpeduncular cistern & Incidental & Primitive trigeminal artery & Detachable coils, incomplete & 7 \\
\hline 4 & 40/M & Sylvian fissure & $\mathrm{ICH}$ & MCA, 3 arterial connections & $\begin{array}{l}\text { (IV), detachable coils, } \\
\text { complete }\end{array}$ & 7 \\
\hline 5 & 14/M & $\begin{array}{l}\text { Anterior aspect of interhemispheric } \\
\text { fissure }\end{array}$ & Seizure & A2 segment of ACA & $\begin{array}{l}\text { (II), detachable coils, } \\
\text { complete }\end{array}$ & 3 \\
\hline 6 & $7 / \mathrm{M}$ & $\begin{array}{l}\text { Posterior aspect of interhemispheric } \\
\text { fissure }\end{array}$ & Headaches & P4 segment of PCA & Detachable coils, complete & 12 \\
\hline 7 & $35 / \mathrm{M}$ & Third ventricle & $\mathrm{ICH}$ & $\begin{array}{l}\text { Posterior medial choroidal arteries } \\
\text { of PCAs }\end{array}$ & $\begin{array}{l}\text { Detachable coils and } 34 \% \\
n-\mathrm{BCA} \text {, complete }\end{array}$ & 6 \\
\hline 8 & $22 / F$ & Quadrigeminal cistern & $\mathrm{ICH}$ & P3-P4 segment of PCA & Fiber coils, incomplete & 3 \\
\hline 9 & $2 / \mathrm{M}$ & $\begin{array}{l}\text { Anterior aspect of interhemispheric } \\
\text { fissure }\end{array}$ & Incidental & A2 segment of ACA & Detachable coils, complete & 6 \\
\hline
\end{tabular}

Note:-BAVFs indicate brain arteriovenous fistulas; R, right; L, left; F, female; M, male; MCA, middle cerebral artery; PCA, posterior cerebral artery; ACA, anterior cerebral artery; $n$-BCA, $n$-butyl cyanoacrylate; ICH, intracranial hemorrhage; II, IV, 2 times and 4 times.

${ }^{*}$ All patients were cured on follow-up.

lesions had associated arterial aneurysms. The venous drainage was deep in 6 lesions.

\section{Endovascular Treatment}

The treatments for each of the 9 patients are listed in the Table. Treatment was endovascular in all patients. Endovascular treatment was via the transarterial transfemoral method. Standard techniques of digital subtraction angiography with "road-mapping" were used, as was superselective angiography when possible. Heparin was used routinely according to protocol to prevent thromboembolic complications during and after the procedure. Wire-guided microcatheters (Echelon, ev3, Irvine, Calif; Excelsior, Target Therapeutics, Fremont, Calif) of various sizes were used to deliver detachable coils (Microplex, Microvention, Aliso Viejo, Calif; Guglielmi detachable coils, Boston Scientific; NXT fiber coils, ev3) or a combination with $34 \% n$-butyl cyanoacrylate ( $n$-BCA; Glubran) to embolize the AV connection. If Onyx (Onyx Liquid Embolic System; ev3) were to be used, a dimethyl-sulfoxide compatible microcatheter (Marathon, ev3) would be used. Detachable coils would be repositioned until a stable and safe position was obtained and, therefore, distal embolization could be eliminated. In addition, coils can act as a template for the deposition of other embolic materials such as glue. We did not choose the $3 \mathrm{D}$ coils because they were more likely to migrate with the flow. We usually used soft 2D coils, larger than the feeding artery in size. If the fistula was high flow, hemodynamic rearrangements of the cerebral circulation predisposed to edema, infarction, and hemorrhage in the brain after occlusion or resection of the lesions. Stepwise reduction of the flow in AVFs is thought to reduce these complications. The high-flow fistula was defined as a dilated feeding artery; the distal territory of the feeding artery was not filled well, and venous drainage would appear at the early arterial phase. A control angiogram would be performed after 3 months. If the fistula was still persistent, it would be treated again. Heparinization was continued for the next 24 hours after the procedure, and low-molecular-weight heparin was medicated subcutaneously until the patient's headaches disappeared. Blood pressure was controlled strictly after embolization. The mean arterial pressure was kept at approximately $75 \mathrm{~mm} \mathrm{Hg}$ for 48 hours after the embolization.

\section{Results}

The lesions in our 9 patients ( 2 female, 7 male; mean age, 17.8 years; age range, $2-40$ years) were diagnosed as BAVFs. The presenting symptoms are documented in the Table. The presentations leading to diagnosis were intracranial hemorrhage, ${ }^{20}$ headaches, ${ }^{21}$ seizure,${ }^{5}$ and no symptoms (2 patients). The location of the hemorrhage was intracerebral in 1 patient, intracerebellar in 1, and subarachnoid in 2 patients. No patients experienced neurologic deficits as a result of intracranial hemorrhage.

The topography of the lesions is listed in the Table. False venous aneurysms were found in all AVFs. There was no dural sinus stenosis, pial vein reflux, or flow-related arterial aneurysms. Eight lesions were single AVFs, and 1 lesion had 3 feeders converging toward a single pouch. The lesions were supratentorial and supplied by the branches of the anterior cerebral artery (ACA) in 4 patients, the middle cerebral artery in 1 patient, the posterior cerebral artery in 2 patients, and the basilar artery in 1 patient. Eight lesions were drained supratentorially and 1 drained supertentorially and infratentorially.

Seven patients were treated with detachable coils alone, 1 with Onyx-34 and 1 by a combination of coils and $n$-BCA. A single embolization session was performed in 7 patients, of which complete obliteration was obtained immediately in 4 patients. One patient was cured with 2 procedures, and another patient was cured with 4 procedures. A single pedicle was embolized in 7 patients, 2 in 1 patient, and 3 in 1 patient.

With a mean clinical follow-up of 5.7 months (range, 3-12 months), all patients were categorized as neurologically excellent without any symptoms (modified Rankin Scale, 0). Follow-up angiography was also performed at 3 to 12 months (mean, 5.7 months). Three lesions which were initially treated thrombosed spontaneously, and the other 6 lesions were com- 

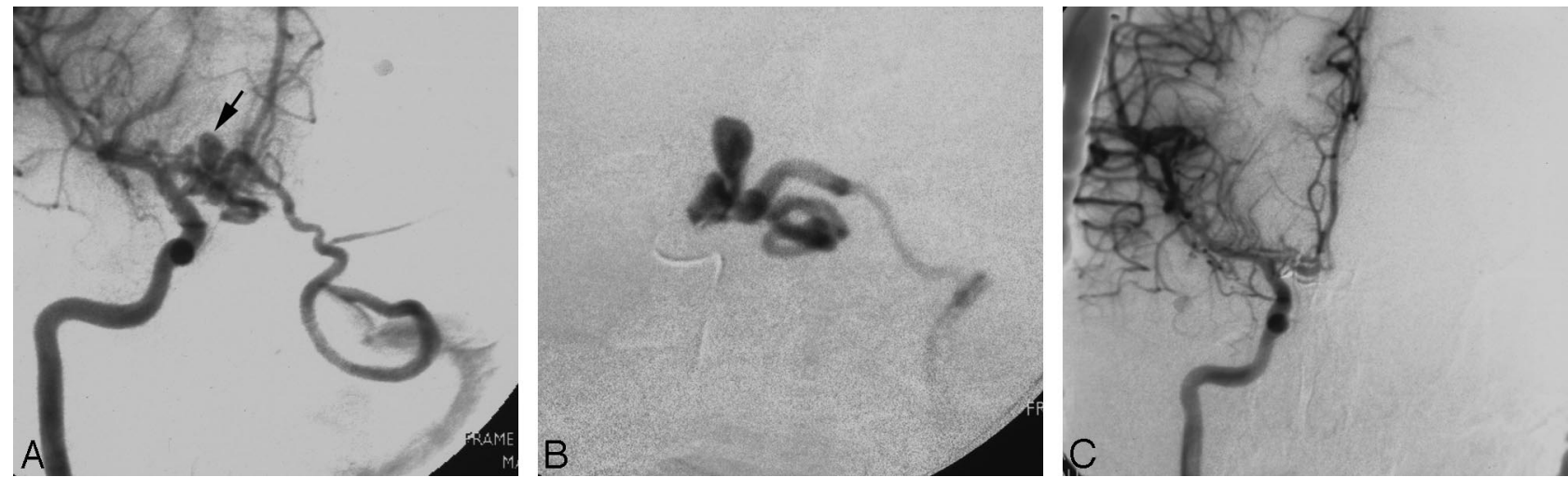

Fig 1. Patient 1. A, Angiogram of right internal carotid injection, anteroposterior view, shows a conglomerate of abnormally dilated vessels at the A1/A2 junction of the right ACA with a venous aneurysm (arrow). The lesion drains into the left sigmoid sinus and sphenoparietal sinus contralaterally via the right frontal basal vein and left tentorial sinus. $B$, Superselective angiography shows an arteriovenous fistula. $C$, Control angiogram of the right internal carotid injection after Onyx embolization, anteroposterior view, shows that the fistula was obliterated completely.
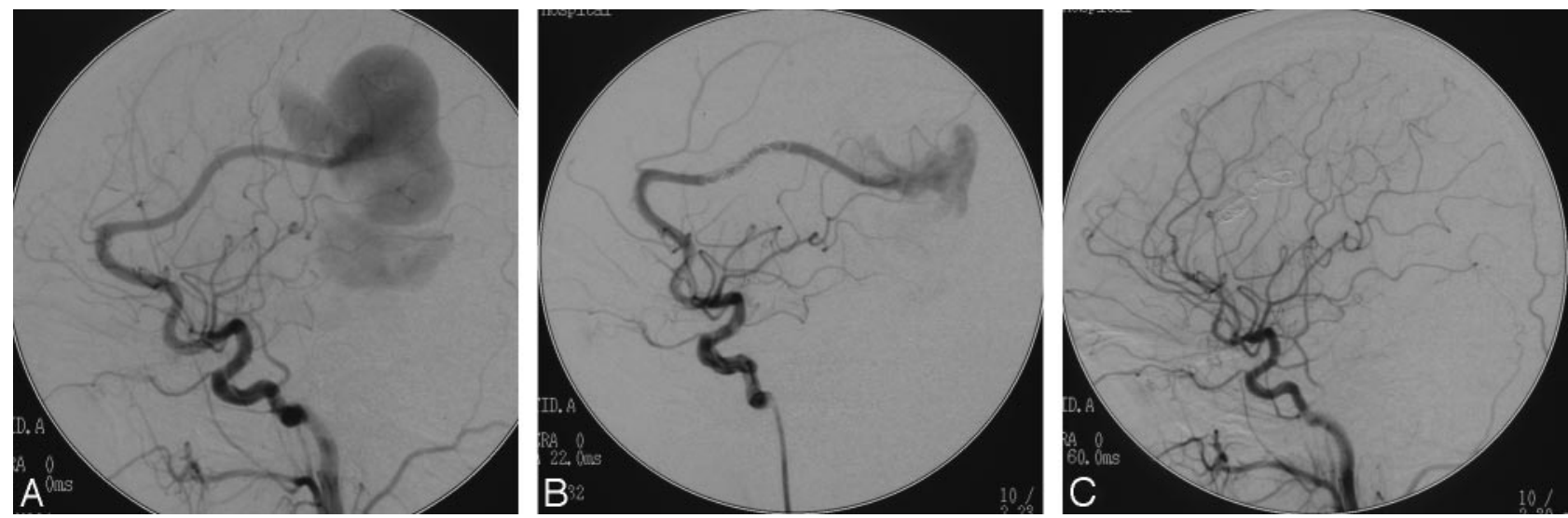

Fig 2. Patient 2. A, Angiogram of left internal carotid injection shows a pial AVF supplied by the left distal ACA with a giant venous aneurysm. $B$, Angiogram of the left internal carotid injection after the procedure shows that the fistula is occluded partially. $C$, Control angiogram at 4-month follow-up shows the fistula thrombosis spontaneously.

pletely obliterated at follow-up angiographic study. In all 9 patients, disconnection of the AV shunt resulted in obliteration of the abnormality of draining vein.

\section{Illustrative Cases}

Patient 1. A 7-year-old boy presented with intracranial hemorrhage. Diagnostic cerebral angiography showed pial fistula with an aneurysmal venous dilation, fed by the right ACA at the junction of $\mathrm{A} 1$ and $\mathrm{A} 2$ and drained into the left sigmoid sinus (Fig 1A). A 0.5-mL Onyx-34 injection was delivered via a Marathon microcatheter (Fig $1 B$ ). The anteroposterior view of the right internal carotid artery angiogram demonstrated complete obliteration of the fistula (Fig 1C).

Patient 2. A 26-year-old woman presented with headaches. Cerebral angiography showed a giant venous aneurysm, nourished by the left ACA (Fig 2A). Two detachable coils $(10 \times 30$ Orbit, Cordis, Miami Lakes, Fla; $12 \times 30$, Microvention) were placed proximal to the fistula via an Echelon 14 (ev3) microcatheter (Fig $2 B$ ), and complete occlusion of the fistula was achieved spontaneously after 4 months (Fig 2C).

Patient 3. A 7-year-old boy presented with mild head trauma. MR imaging showed a giant flow-void signal intensity in the front of the midbrain, which suggested a vascular lesion (Fig 3A). Cerebral angiography showed a large aneurysmal venous dilation, nourished by the primitive trigeminal artery from the basilar artery and drained into the basal vein of Rosenthal (Fig 3B). A $20 \times 50$-mm detachable coil (Microvention) was deployed via a microcatheter (Excelsior, Boston Scientific; Fig 3C). After 7 months, a left vertebral artery angiogram demonstrated complete occlusion of the fistula (Fig $3 D$ ), and MR imaging showed that the venous aneurysm had disappeared (Fig 3E).

\section{Discussion}

BAVFs of the brain are characterized by an immediate AV transition without a capillary bed or "nidus" as occurs in BAVMs. ${ }^{22}$ BAVFs can result from trauma or may be congenital. ${ }^{3,4}$ Congenital AVFs usually present in childhood (5 of 9 patients in our study were pediatric patients). The pathophysiologic mechanisms giving rise to these lesions is still not clear. ${ }^{1,20,23}$ It is likely that a misstep in embryologic development of the cerebrovasculature produces these lesions. The connection between an arterial feeder directly into a solitary draining vein without any intervening tangle of vessels creates conditions for rapid high flow. The pathologic features of congenital BAVFs arise principally from its high-flow nature. Associated venous varices are produced by the high, turbulent flow from AV shunt surgery. ${ }^{9,10,20,24}$ BAVFs can be asymptomatic or, more often, can cause increased intracranial pressure, seizures, cerebral hemorrhage, neurologic deficit, cardiac 

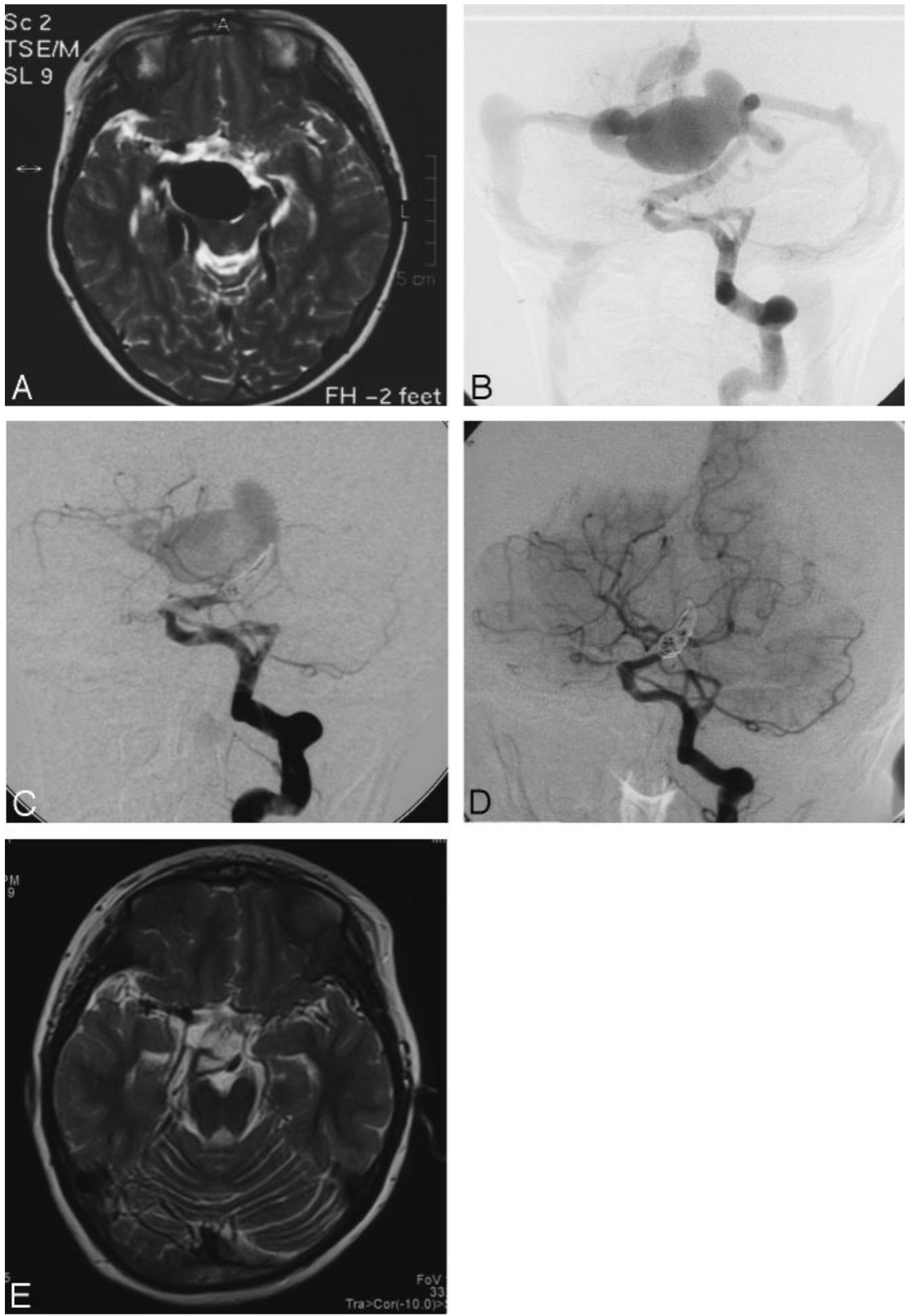

Fig 3. Patient 3. A, T2-weighted MR imaging of the head at the level of the midbrain shows giant flow-void signal intensity in the interpeduncular cistern. $B$, Anteroposterior view of the left vertebral artery injection demonstrates that the fistula is supplied by the primitive trigeminal artery and drained into the basal vein of Rosenthal, with an associated venous varix. $C$, After coil embolization, anteroposterior view of the left vertebral artery injection demonstrates incomplete disconnection of the fistula by the coils. $D$, Follow-up angiogram obtained at 7 months shows spontaneous occlusion of the fistula with preserved patency of the basilar artery. E, Disappearance of the venous varix on follow-up T2-weighted MR imaging.

failure in neonates and infants, and intracranial bruit for which treatment is necessary. ${ }^{5-8,10}$ They can also be part of a syndrome such as Klippel-Trenaunay-Weber or RenduOsler-Weber (hereditary hemorrhagic telangiectasia). ${ }^{17,25-27}$ The risk for hemorrhage from BAVFs is not clear. ${ }^{8}$ Singlevenous drainage and small size have been thought to contribute to the risk for BAVM hemorrhage, ${ }^{28}$ both of which are characteristics of pial AVFs. However, it is not clear whether venous varices and venous drainage (superficial or deep) associated with pial AVFs are associated with an increased risk for hemorrhage.

Once the connection to the high-flow system is eliminated, so is the abnormality and any accompanying elements (such as venous varices). The preferred treatment of BAVF is interruption of the fistula or obliteration of all feeding vessels as close to the fistula as possible, while leaving the venous drainage intact. ${ }^{2,3}$ Because there is no nidus, surgical clipping for disconnection of the AV shunt should eliminate the abnormality without the necessity for resection of the lesion. ${ }^{14}$ Removal of the varix is not attempted unless the malformation bleeds with a resultant hematoma, or the accessible varix produces a mass effect. ${ }^{29}$ This has proved effective; however, sometimes this procedure is impossible because of the deep location and difficulty in exposure. ${ }^{3}$ In addition, as a result of the longstanding shunt, arterialization and thickening of the draining veins can occur, making identification of the exact fistula site more difficult. Lesions in deep and eloquent locations can be associated with a high surgical risk for neurologic morbidity. Also, deep hypothermic cardiopulmonary bypass will be needed to perform surgical resection of such technically difficult le- 
sions. ${ }^{29,30}$ With a surgical approach, it may also be difficult to localize the lesion intraoperatively because the fistula can be quite small and is not associated with a nidus or tangle of vessels to help in visual identification.

Endovascular applications have been reported as successful ways to disconnect AVFs with several different agents such as balloons, coils, glue, and Onyx..$^{3,9,21,23,31-33}$ When the lesion is surgically risky, at a deep or inaccessible location, we use endovascular techniques because we find them to be safe and effective. Endovascular treatment can be implemented in stages, and it may reduce the risk for postoperative hemorrhage, possibly by preventing normal perfusion pressure breakthrough in high-flow lesions. Even a single venous channel has multiple arterial connections; therefore, it is possible to eliminate the AVF from a transarterial approach. In our series, patient 4 had 3 arterial connections, and he underwent transarterial embolization in 4 stages that resulted in complete obliteration of the fistula. Detachable coils are useful because they can be repositioned until a stable and safe position is obtained; therefore, distal embolization can be eliminated or minimized. In addition, they can act as a template for the deposition of other embolic materials, such as glue. The use of a high concentration of $n$-BCA or pure $n$-BCA in high-flow shunts for brain AVMs may occlude the fistula within seconds because the flow of $n$-BCA is, to some extent, unpredictable. Inadvertent migration of the glue into the draining veins may result in immediate hemorrhage by blocking venous outflow. We inserted detachable coils at the fistula site to decrease the flow and thereby facilitate the injection of $n$-BCA in patient 7 .

Recently, the new liquid embolic agent Onyx has become available for embolization of brain AVMs. Onyx is nonadhesive and polymerizes slowly. Onyx is available in several concentrations, and the high-concentrated Onyx can be used to slowly occlude small AV shunts in a more controlled way than that achieved with $n$-BCA. However, a simple Onyx injection is not always feasible; in some very high-flow shunts, Onyx may migrate through the fistula into the distal draining veins. Adjuvant use of a microballoon to block the flow to enable gradual occlusion of the large high-flow shunts with Onyx has been reported. ${ }^{21,32}$ We believe that this abrupt disconnection may result in hyperemia on evocation of the normal perfusion pressure breakthrough phenomenon.

The endovascular management of AVFs is challenging because of the high flow through the fistula and the large size of the afferent and efferent vessels. Hemodynamic derangements of the cerebral circulation predispose to edema, infarction, and hemorrhage in the brain after resection of the lesions. ${ }^{34-36}$ Fortunately, we did not encounter this problem in the treatment of our 9 patients. In high-flow fistulas, we initially coiled them partially and the patient was observed. After 3 months, control angiography would be obtained. Spontaneous thrombosis will develop in some patients; if not, another embolization will be performed. Also, in our series, no morbidity or mortality occurred. If the embolization is too proximal to the $\mathrm{AV}$ connection, the fistula is only partially obliterated, or new arterial connections can be recruited with recurrence of the fistula. ${ }^{3}$ In general, we place the coils proximal to the fistula point. Although some authors suggest that the endovascular occlusion of the BAVF is difficult compared with placement of detachable platinum coils ${ }^{14,17,21,37}$ and embolic agent depos- its, we obtained good angiographic outcome in all patients. There are several reports of unsuccessful attempts at endovascular embolization of an AVF because of migration of the embolization agent into a varix; into the lung; or, most dangerously, into the draining vein or elsewhere in the cerebral vasculature..$^{3,21,37}$ In our series, there was no such event.

Regardless of the agent used, it is important to consider that a complete fistula cure may produce devastating complications from extensive thrombosis of the draining veins initially arterialized and a risk for venous infarction or hemorrhage. Therefore, the patients who presented with headaches after embolization were treated with intravenous heparin, aimed at achieving an activated clotting time of twice the normal value for 24 hours postoperatively, and then low-molecular-weight heparin at a preventive dose for 2 to 15 days until the headaches were alleviated.

\section{Conclusions}

From our experience and that of others, with the advent of recent endovascular techniques, a number of groups have been convinced of the application of endovascular therapies to treatment of BAVFs. Different types of high-flow AV shunts can safely be occluded with endovascular techniques tailored to the specific anatomic configuration of the shunt.

\section{References}

1. Hung PC, Wang HS: Successful endovascular treatment of cerebral arteriovenous fistula. Pediatr Neurol 2002;27:300-02

2. Weon YC, Yoshida Y, Sachet M, et al. Supratentorial cerebral arteriovenous fistulas (AVFs) in children: review of 41 cases with 63 non choroidal singlehole AVFs. Acta Neurochir 2005;147:17-31

3. Halbach VV, Higashida RT, Hieshima GB, et al. Transarterial occlusion of solitary intracerebral arteriovenous fistulas. AJNR Am J Neuroradiol 1989;10:747-52

4. Santosh C, Teasdale E, Molyneux A. Spontaneous closure of an intracranial middle cerebral arteriovenous fistula. Neuroradiology 1991;33:65-66

5. Almeida GM, Shibata MK: Hemispheric arteriovenous fistulae with giant venous dilation. Childs Nerv Syst 1990;6:216-19

6. Aoki N, Sakai T, Oikawa A: Intracranial arteriovenous fistula manifesting as progressive neurologic deterioration in an infant: case report. Neurosurgery 1991;28:619-23

7. Garcia-Monaco R, De Victor D, Mann C, et al. Congestive cardiac manifestations from cerebrocranial arteriovenous shunts: endovascular management in 30 children. Childs Nerv Syst 1991;7:48-52

8. Kader A, Young WL, Pile-Spellman J, et al. The influence of hemodynamic and anatomic factors on hemorrhage from cerebral arteriovenous malformations. Neurosurgery 1994;34:801-08

9. Lv X, Li Y, Lv M, et al. Successful endovascular treatment of a deep cerebral arteriovenous fistula with unusual venous drainage. Eur J Radiol Extra 2008;68:e53-58

10. Martin NA, Macagba-Crain CL, Geffner $M$ et al. Isolated growth hormone deficiency associated with a giant arteriovenous varix. Neurosurgery 1990;27:295-99

11. Viñuela F, Drake CG, Fox AJ, et al. Giant intracranial varices secondary to high-flow arteriovenous fistulae. J Neurosurg 1987;66:198-203

12. Bikmaz K, Erdem E, Krisht A. Arteriovenous fistula originating from proxima part of the anterior cerebral artery. Clin Neurol Neurosurg 2007; 109:589-91

13. Halbach VV, Dowd CF, Higashida RT, et al. Endovascular treatment of muraltype vein of Galen malformations. J Neurosurg 1998;89:74-80

14. Hoh BL, Putman CM, Budzik RF, et al. Surgical and endovascular flow disconnection of intracranial pial single-channel arteriovenous fistulae. Neurosurgery 2001;49:1351-64

15. Kakino S, Ogasawara K, Kubo Y, et al. Spontaneous pial single-channel arteriovenous fistulae with angiographically occult small feeding arteries: case report. Surg Neurol 2008;69:187-91

16. Morimoto T, Yamada T, Hashimoto $\mathrm{H}$, et al. Direct approach to intracranial vertebral arteriovenous fistula: case report. Acta Neurochir (Wien) 1995;137:98-101

17. Passacantilli E, Pichierri A, Guidetti G, et al. Surgical treatment of pial cerebellar arteriovenous fistulas with aneurysm of the main feeding artery. Surg Neurol 2006;65:90-94 
18. Talamonti G, Versari PP, D'Aliberti G, et al. Complex arteriovenous fistula of the brain in an infant: case report. J Neurosurg Sci 1997;41:337-41

19. Tomlinson FH, Rufenacht DA, Sundt TM Jr, et al. Arteriovenous fistulas of the brain and the spinal cord. J Neurosurg 1993;79:16-27

20. Barnwell SL, Ciricillo SF, Halbach VV, et al. Intracerebral arteriovenous fistulas associated with intraparenchymal varix in childhood: case reports. Neurosurgery 1990;26:122-25

21. Andreuo A, Ioannidis I, Nasis N. Transarterial balloon-assisted glue embolization of high-flow arteriovenous fistulas. Neuroradiology 2008;50:267-72

22. Wang YC, Wong HF, Yeh YS. Intracranial pial arteriovenous fistulas with single-vein drainage. Report of three cases and review of the literature. J Neurosurg 2004;100 (2 Suppl Pediatrics):201-05

23. Nelson K, Nimi Y, Lasjaunias P, et al. Endovascular embolization of congenital intracranial pial arteriovenous fistulas. Neuroimaging Clin $N \mathrm{Am}$ 1992;2:309-17

24. Halliday AL, Ogilvy CS, Crowell RM: Intracranial vertebral arteriovenous fistula: case report. J Neurosurg 1993;79:589-91

25. Garcia-Monaco R, Taylor W, Rodesch G, et al. Pial arteriovenous fistula in children as presenting manifestation of Rendu-Osler-Weber disease. Neuroradiology 1995;37:60-64

26. Kikuchi K, Kowada M, Sasajima H. Vascular malformations of the brain in hereditary hemorrhagic telangiectasia (Rendu-Osler-Weber disease). Surg Neurol 1994;41:374-80

27. Oda M, Takahashi JA, Hashimoto N, et al. Rendu-Osler-Weber disease with a giant intracerebral varix secondary to a high-flow pial AVF: case report. Surg Neurol 2004;61:353-56

28. Spetzler RF, Hargraves RW, McCormick PW, et al. Relationship of perfusion pressure and size to risk of hemorrhage from arteriovenous malformations. J Neurosurg 1992;76:918-23

29. Bendok BR, Getch CC, Frederiksen J, et al. Resection of a large arteriovenous fistula of the brain using low-flow deep hypothermic cardiopulmonary bypass: technical case report. Neurosurgery 1999;44:888-91

30. Meyer FB, Grady RE, Abel MD, et al. Resection of a large temporooccipital parenchymal arteriovenous fistula by using deep hypothermic circulatory bypass: case report. J Neurosurg 1997;87:934-39

31. Smith MD, Russell EJ, Levy R, et al. Transcatheter obliteration of a cerebellar arteriovenous fistula with platinum coils. AJNR Am J Neuoradiol 1990;11:1199-202

32. Viñuela F, Fox AJ, Kan S, et al. Balloon occlusion of a spontaneous fistula of the posterior inferior cerebellar artery: case report. J Neurosurg 1983;58:287-89

33. van Rooij WJ, Sluzewski M. Endovascular occlusion of high-flow intracranial arteriovenous shunts: technical note. Neuroradiology 2007;49:1029-31

34. Giller CA, Batjer HH, Purdy P, et al. Interdisciplinary evaluation of cerebra hemodynamics in the treatment of arteriovenous fistulae associated with giant varices. Neurosurgery 1994;35:778-84

35. Halbach VV, Higashida RT, Hieshima GB, et al. Normal perfusion pressure breakthrough occurring during treatment of carotid and vertebral fistulas. AJNR Am J Neuoradiol 1987;8:751-56

36. Spetzler RF, Wilson CB, Weinstein P, et al. Normal perfusion pressure breakthrough. Clin Neurosurg 1978;25:651-72

37. Hyodo A, Yanaka K, Kato N, et al. Coil migration during endovascular treatment in a patient with Galenic arteriovenous malformation. J Clin Neurosci 2002;9:584-85 